\title{
GEOMECHANICAL MODEL AND SANDING ONSET ASSESSMENT: A FIELD CASE STUDY IN VIETNAM
}

\author{
Nguyen Van Hung, Bui Thi Thuy Linh \\ Petrovietnam University \\ Email: hungnv@pvu.edu.vn \\ https://doi.org/10.47800/PVJ.2021.10-04
}

\section{Summary}

Sand production is a key issue when selecting and applying completion solutions like open holes, screens or perforated liners. This problem can be seen in several types of reservoirs such as weakly consolidated and non-consolidated carbonates. The paper presents a method to model wellbore failures for sanding prediction. Our study shows that the potential sand risk in this field is defined by the rock strength rather than the in-situ stress. If the rock is sufficiently competent, the potential of sand production is negligible and the development wells can be completed conventionally without any downhole sand control for the reservoir pressure above 1,280 psi and the maximum drawdown pressure of 2,380 psi.

Key words: Sand production, in-situ stress, sand control.

\section{Introduction}

Mitigation of sand production is an important and challenging issue in the petroleum industry which requires sand control decision-making. Although approximately $60 \%$ of the world's oil and gas production comes from carbonates, about $70 \%$ of the petroleum reservoirs worldwide are located in sandstone formations where sand production can be a potential problem [1]. Some carbonate reservoirs may also produce solids [2]. In complex reservoir conditions such as deepwater, high temperature, high pressure, there are always problems (produced sand, hydrates, scale, wax/asphaltene, etc.). Sand production can lead to erosion, loss of integrity and potential fatalities. Applying different methods of sand control usually causes a reduction in well productivity and increasing cost of well.

Sanding is caused by the disaggregation of formation rock because of the in-situ stress and the fluid hydrocarbon flow from a weakly consolidated and nonconsolidated sandstone reservoir. The sand production process can be divided into three stages: (i) rock matrix failure and opening hole or perforation from which free

Date of receipt: 9/9/2021. Date of review and editing: 9/9 - 30/9/2021. Date of approval: 7/10/2021. sand grains are generated, (ii) detachment of sand grains from failed rock, and (iii) transportation of free grains by reservoir effluents into the wellbore and up to the surface [3]. There are several elements which must be considered to understand the mechanism of sand production that occurs, including near wellbore stress, rock and fluid properties, rock composition, drilling and production operations and geological conditions. Under the initial condition, a virgin formation will be unchanged in its stress state. Perforation or completion of the formation would change the stress state around the perforation hole.

Sand production prediction is important, and traditional remedies used in petroleum engineering today are based on field observation and experience, laboratory experiments and numerical modelling. In recent years, neural network-based techniques evolved through the work of Kanj and Abousleima [4]. The observation and empirical methods attempt to establish a correlation using multi-variable linear regression between the data collected from a sand producing well and the operational and field parameters (production rate, drawdown) relating to reservoir formation, well completion and production. Several projects have been conducted to predict sand production based on the critical stress state at which failure occurs. Tensile failure appears when 
effective stress in the rock exceeds its tensile strength, which is mostly applicable in high-rate oil and gas wells. For this group, it is generally assumed that a critical flowrate or drawdown exists which is sufficient to break up the material in tension. This mode of failure can best be visualised in relatively uncemented (commonly referred to as an unconsolidated or weakly consolidated) materials where under right seepage forces the cementation can be broken, leading to transport of sand grains. Such models generally render a maximum drawdown that should not be exceeded. Their practical application has mostly been used for predicting the early life drawdown as the effect of depletion is not rigorously factored into the equations thus making their applications in late life situations unconservative. Shear failure occurs when the tangential stress along the shear plan exceeds a critical value, which depends on the normal stress.

Various failure criteria in terms of functions of the effective stress have been developed. For example, the Mohr-Coulomb, Hoek Brown, Druker-Prager, Lade, and Mogi-Coulomb, Weibols and Cook, Griffith, Tresca criteria are used as the shear failure models for sanding onset [5]. Rock mechanical properties are essential for accurate in-situ stress analysis and geomechanical evaluation including wellbore stability analysis, sand production prediction and management, hydraulic fracturing design, fault stability and reactivation analysis, and other geomechanical applications. The rock mechanical parameters typically recommended to populate a geomechanical model are: unconfined compressive strength (UCS), friction angle ( $\theta$ ) or coefficient of internal friction $(\mu)($ where $\mu=\tan \theta)$, thick wall cylinder strength (TWC), elastic moduli (Poisson's ratio (v), and Young's modulus (E)). While the mechanical parameters can be derived from well logs (bulk density, compressional and shear sonic logs) and laboratory tests on core samples, laboratory measurements of the elastic moduli (triaxial tests) on core samples subjected to the in-situ stress condition are also correlated with well logs to derive a continuous strength profile as a function of depth.

\section{Sanding onset workflow}

The key feature in sand production prediction is a geomechanical model that consists of field stresses $\left(\sigma_{v^{\prime}}\right.$ $\left.\sigma_{\mathrm{H}^{\prime}} \sigma_{\mathrm{h}}\right)$, pore pressure $\left(\mathrm{P}_{\mathrm{p}}\right)$, direction of $\sigma_{\mathrm{H}^{\prime}} \sigma_{\mathrm{h}^{\prime}}$ rock strength and elastic moduli [6]. The vertical stress is calculated by integrating the density $\log \left(\rho_{b}\right)$ or sonic log. In the absence of both log data, lithological and regional information can be used to approximate $\sigma_{\mathrm{v}}$. The least principal stress is usually evaluated from leak-off tests (LOTs), extended LOTs (ELOTs), or minifrac tests. While a minifrac test is conducted with a particular objective of measuring the minimum horizontal stress in a field, LOTs and ELOTs are usually carried out as part of a drilling programme. In addition, $\sigma_{\mathrm{h}}$ can be estimated from $\sigma_{\mathrm{v}}$ and Poisson's ratio by using its relationship or this approach assumes that the ratio between the vertical effective stress and the minimum horizontal effective stress remains constant with depth. The use of regional information and empirical models for $\sigma_{h}$ is also useful where reliable field data are not available.

The direction of horizontal stresses is determined from borehole breakout observation, multi-arm calliper logs, drilling-induced tensile fractures (DITF) in high resolution image logs, and transmission of shear wave velocity. If these measures are not available, recent tectonic activities in the area of interest and regional stress data such as the world stress map should be valuable sources of information. It is evident that there is no way to measure or determine directly the value of maximum horizontal stress $\sigma_{\mathrm{H}}$. In this situation, the stress polygon method, the linear elastic theory and rock failure criteria for a particular borehole condition should be the good remedies to determine $\sigma_{H}$. Pore pressure is estimated directly from measurements in permeable and reservoir zones such as repeat formation tester (RFT), drillstem test (DST). For sands, the pressures are modelled using buoyancy estimations and depletion, when applicable. It is also important to determine the top of overpressure if any.

The uniaxial compressive rock strength (UCS) profile is determined based on the rock mechanical testing data. There are some references models which can be used: UCS $=1.35 V_{p}^{2.6}$ (for shale), UCS $=185165 \mathrm{e}^{-0.037^{*} \text { DTCO }}$ (for sandstone). The internal friction for lithologies in some cases can be assumed constant 0.4 (for shale), and 0.5 (for sandstone). The Poisson's ratio is 0.2 and 0.3 for sand and shale, respectively.

The geomechanical workflow, as shown in Figure 1, is represented as a series of 10 interdependent steps. The sequence reflects a logical progression of data processing, each step builds upon one or more preceding steps [6].

Sanding onset analysis uses the results of final geomechanical models. These models encompass rock strength profile, initial reservoir pressure, and pressure 


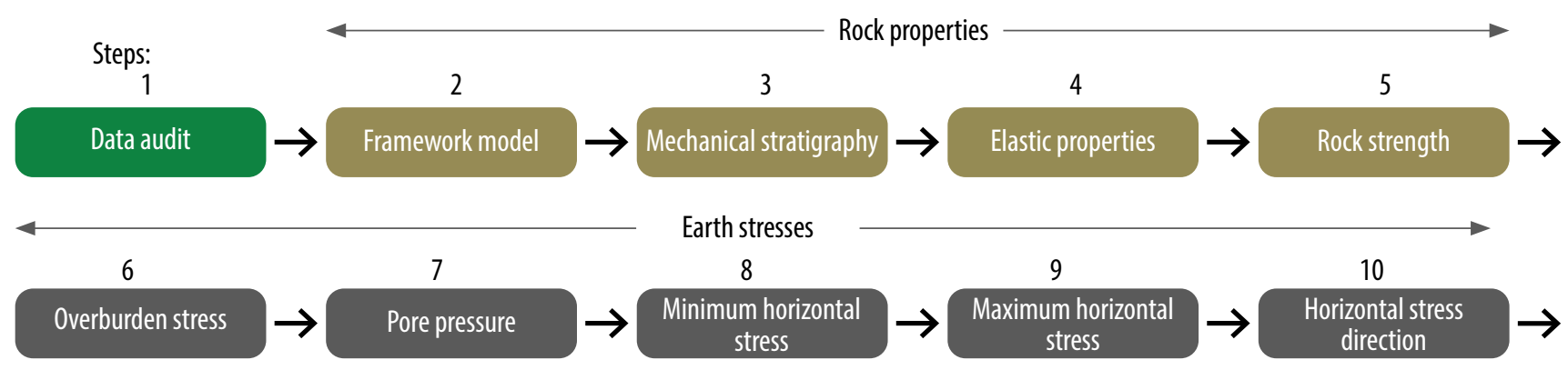

Figure 1. The geomechanical workflow [6].

decline data from the production plan. Then sandfree operating envelopes and sanding evaluation log plots represent specific rock strengths at given depths. The studied reservoir pressure is determined from current drawdown and the planned final abandonment pressures. The sand failure is predicted, and the onset of sand production is assumed from rocks with the specified strength.

\section{Shear failure criteria}

The first method was used in horizontal wells by BP in 1985 [7]. This method predicts sanding as shear failure, and the production of sand grains is accompanied with fluid flow that transfers disaggregated sands. The mathematical representation is given in Equation 1 and the criterion for sanding is:

$$
B H F P \leq\left(3 \sigma_{1}-\sigma_{3}-\sigma_{y}\right) /(2-A)-\operatorname{Pr} A(2-A)
$$

Where CBHFP = critical bottom hole flowing pressure; $P_{r}=$ current average reservoir pressure; $\sigma_{1^{\prime}} \sigma_{3}$ are the total principal major and minor stresses; $\sigma_{y}$ is the effective formation strength $\left(\sigma_{y}=3.1 \times\right.$ TWC); Factor 3.1 includes the scale transformation from TWC laboratory sample $(O D: I D=3)$ to field (OD:ID = infinity); $A$ is the pore elastic constant $(A=(1-2 v) \times \alpha(1-v)) ; \alpha$ is the Biot factor; TWC represents a fundamental measure of strength for an unsupported borehole and perforation.

\section{Tensile failure model}

This mode of failure can be best matched in weakly consolidated sandstone. This model provides a maximum allowable drawdown. Equation 2 shows the relationship between the rock strength and fluid flow in a perforation:

$$
\Delta q=q \mu / 4 \pi k r=C(1+3 \sin \varphi) / \tan \varphi(1-\sin \varphi)
$$

Where $q$ is flow rate, $\mu$ is viscosity, $r$ is perforation radius, $\mathrm{k}$ is permeability, $\varphi$ is angle of internal friction, $C$ is intact rock cohesive strength.
The critical drawdown (CDP) for liquids is:

$$
C D P=4 C \cos \varphi /(1-\sin \varphi)
$$

\section{Case study}

\subsection{Input data}

In order to build the sand production risk model for our proposed production wells, we have collected the following data:

- Geological, petrophysical, logging, drilling, well test, and reservoir data including gamma ray, calliper, neutron porosity, density, resistivity, sonic curves, and dipole logs.

- Geomechanics testing: select rock samples and identify suitable intervals for rock mechanical strength tests.

- In-situ stress model: log data derived strength correlations with strength model from laboratory tests.

- Rock strength model: analysis of density logs, FIT/ LOT/ELOT, minifrac, and borehole failure, such as: UCS/CO, TWC, So, $\theta, E, v, \alpha$.

- Drilling incidents and data from offset wells.

\subsection{Geomechanical model}

\section{TWC model}

Our data collection shows the rock mechanical tests including around 20 UCS and 10 TWC tests. The results are performed in both vertical and horizontal directions. After visual inspection by SEM, X-Ray, and thin-section, we observed that there is no distinct bedding in these cores, so the results from the vertical samples are assumed to be similar to those from the horizontal ones.

The ratio of TWC/UCS from our cores is plotted in Figure 2 and compared with the theoretical model (worldwide data). It can be seen that with hard rocks (UCS $>4,000$ psi), the TWC/UCS ratio is constant at just below 2 . 
However, this ratio increases significantly and can exceed 4 with UCS less than $1,000 \mathrm{psi}$. This is due to the compaction effect which strengthens the core in TWC behaviour, but it is absent in UCS results. Our result data follow a similar trend to the worldwide data with the range of UCS from 2,096 - 5,670 psi but offset slightly towards the lower TWC/ UCS ratios. The model of TWC/UCS ratio from our core tests can be expressed as a function of UCS by Equation 4:

$$
\frac{T W C}{U C S}=87.084 U C S^{-0.457}
$$

Because TWC values are taken directly in the sand production model, the relationship between TWC and elasticity modulus ( $\mathrm{EC})$ is used to derive a functional continuous rock strength. The reasons for selecting Young's modulus are: Ec can be used to predict strength profiles in the development wells (taking DT data) and, more importantly, the correlation coefficient in the crossplot is better. Figure 3 shows the relationship between TWC and Ec resulting in the model:

$$
T W C=2460.2 E c-3209.5
$$

\section{In-situ stress model}

\section{Vertical stress and pore pressure model}

The analytical models provide stress components in cylindrical coordinates such as tangential, radial around the vertical/horizontal/perforation cavity [8]. These are the stresses that cause the rock surrounding the open cavity to fail. The in-situ principal stresses (vertical, major horizontal stress, minor horizontal stress) are the keys. The far-field orientation is pivotal for deviated or horizontal wells. The pore pressure also plays a role in modifying the total stress at any point in the rock into an effective stress. In the research area, the normal pressure regime is 0.433 $\mathrm{psi} / \mathrm{ft}$ over the main intervals of the reservoir in our wells. The vertical stress model is built from density logs $\rho b=$ $a d^{2}-b d+c$, where $d$ is true vertical depth.

Our density data are available for all wells but the best one is illustrated in Figure 4. We have no data measurement in the shallow depth (less than 1,990 $\mathrm{m})$. The model in this figure indicates a consistent and overlying compaction trend for a standard well (from $1,990 \mathrm{~m}$ to $2,532 \mathrm{~m}$ ). For most sedimentary rocks and in our case, the compaction trend can be described as the relationship between bulk density and depth by Equation 6. This model overestimated formation densities near the mud line, and at depths greater than 3,532 $\mathrm{m}$ at TVD. The gradient of overburden is $0.950 \mathrm{psi} / \mathrm{ft}$.

$$
\rho_{b}=14,768 d^{2}-57,808 d+56,858
$$

\section{Minimum horizontal stress}

We applied both direct and theoretical methods. Obviously, the direct field measurement is normally preferred by minifrac test and LOT, FIT. In the FIT test, we verify the quality of the cementing of casing, and the pressure is increased until leak-off occurs to the formation due to fracture initiation. In the LOT test, the pressure goes up until fracture initiation has been seen (FIP or leak-off pressure). There is no signal of mud losses during drilling

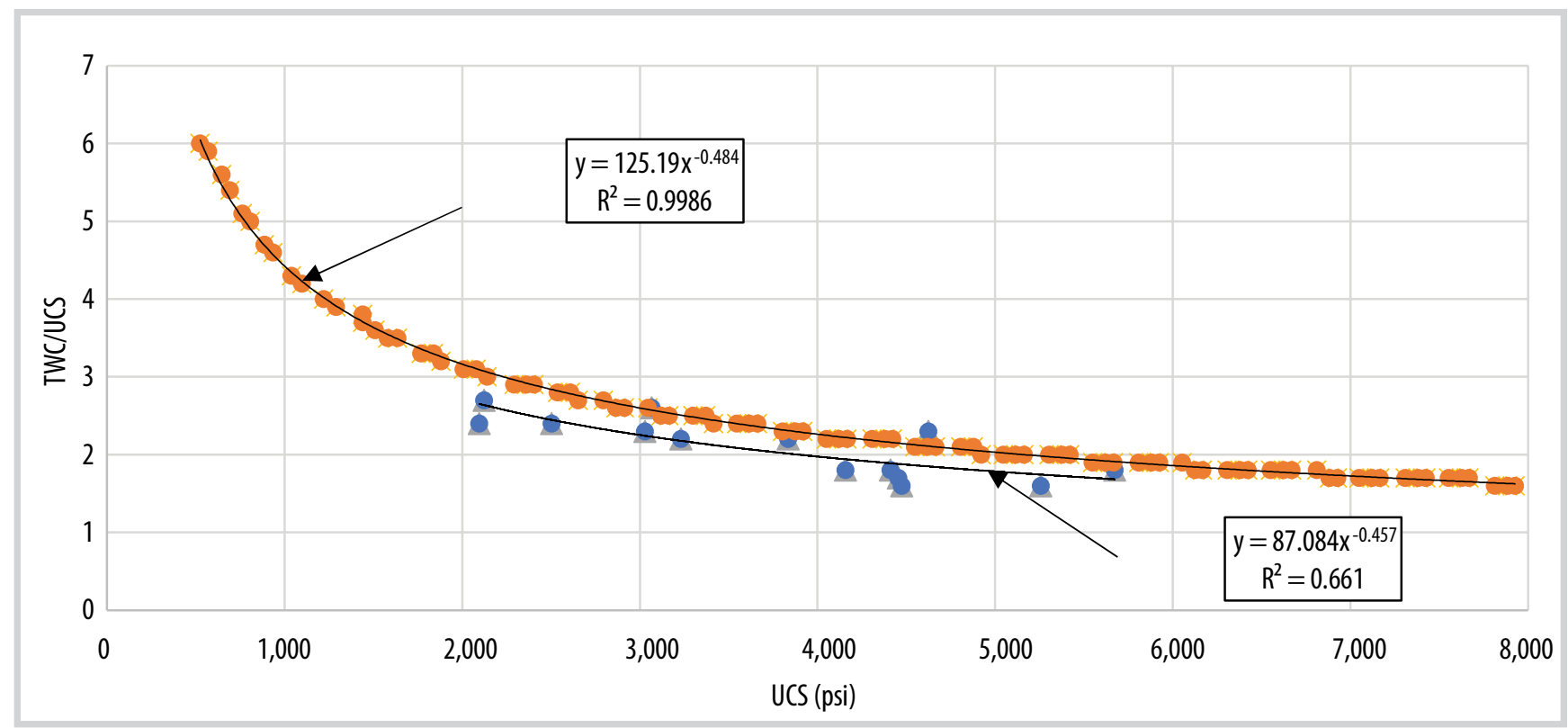

Figure 2. TWC and UCS relationship compared with theoretical model. 


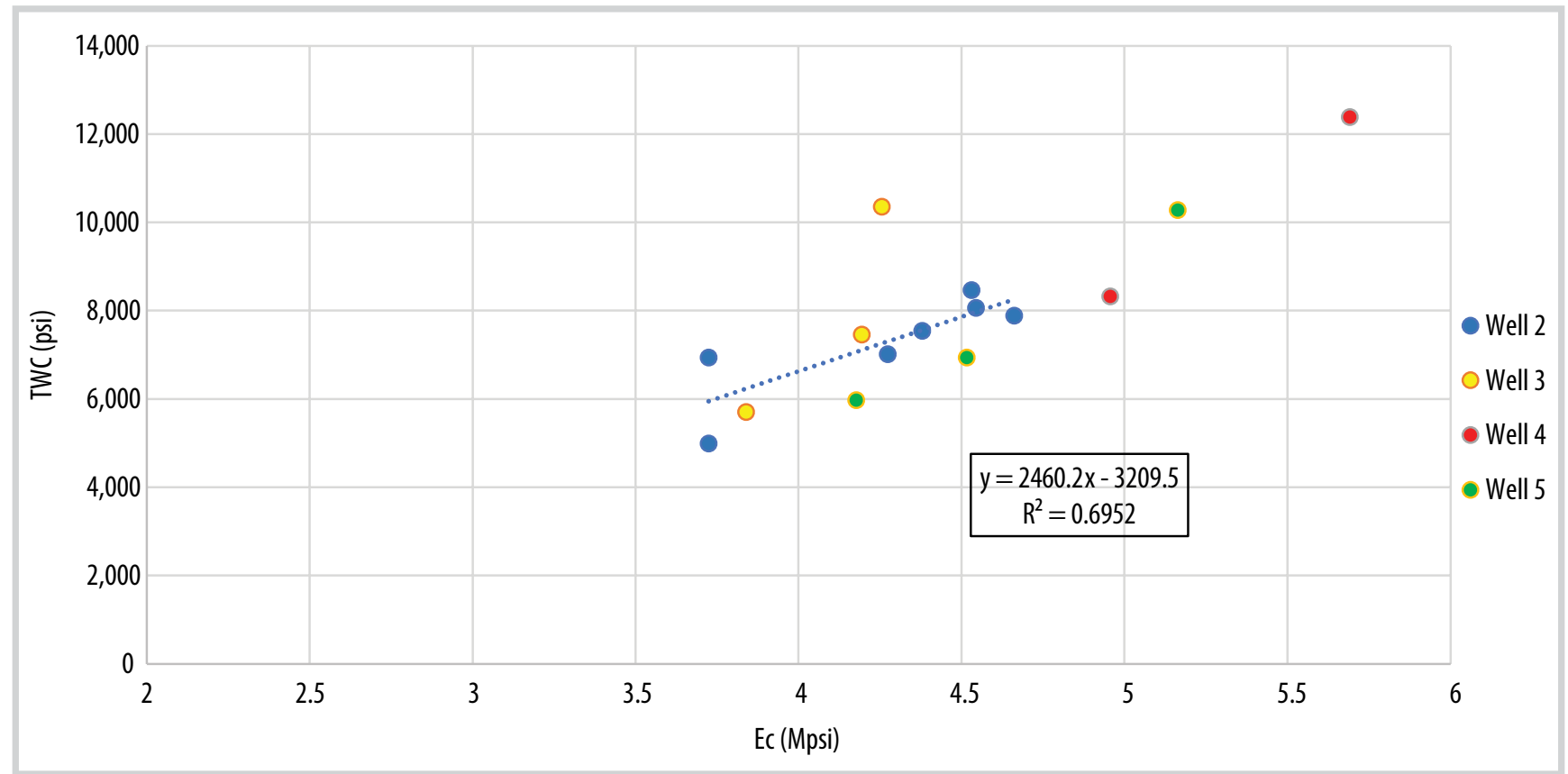

Figure 3. Relationship between TWC and EC.

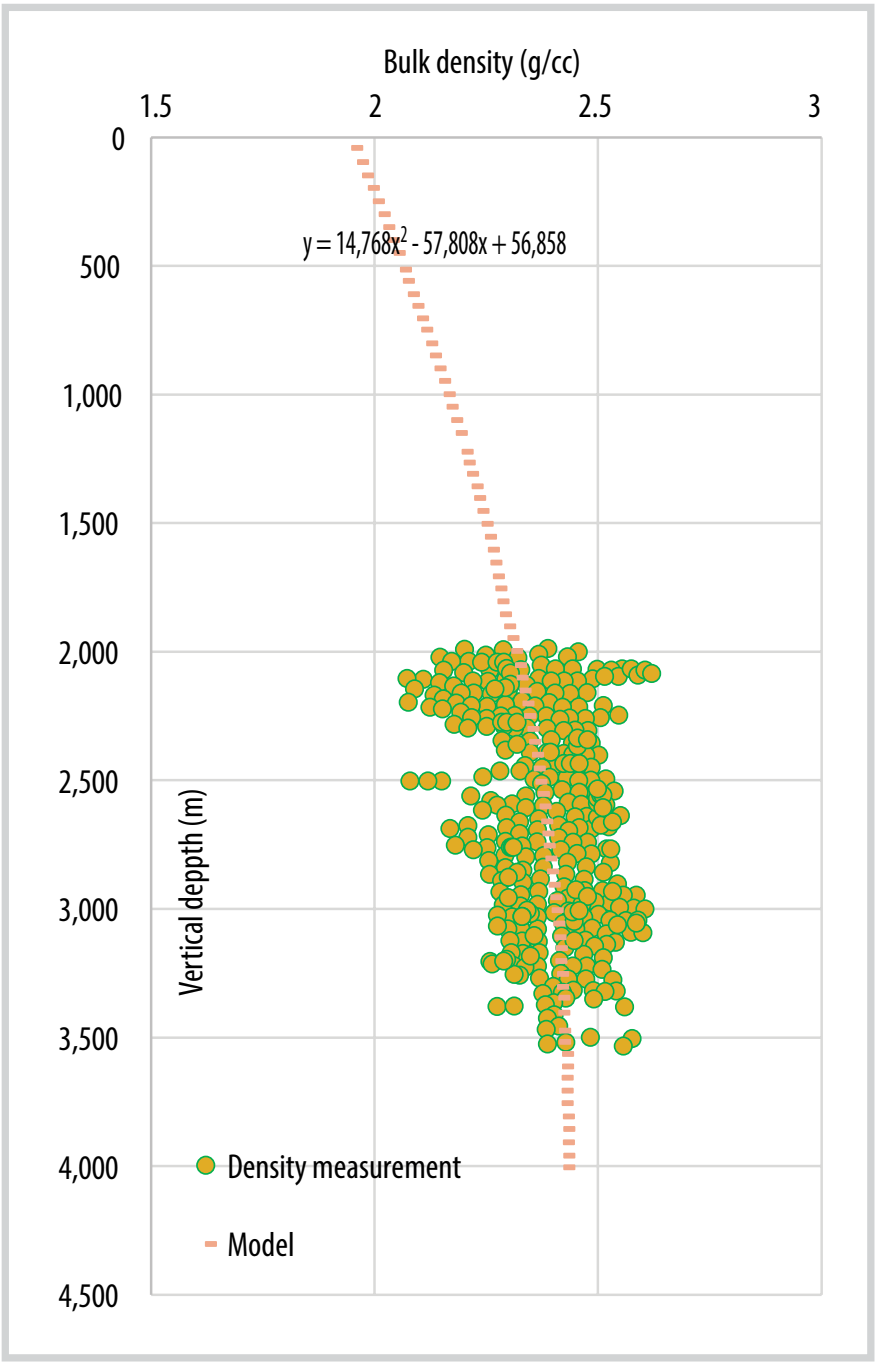

Figure 4. Density versus depth (measurement and model). operations from mud line to $1,990 \mathrm{~m}$ at TVD depth. The uniaxial elastic model provides the calculation of minimum horizontal stress:

$$
\sigma_{h}=\frac{v\left(\sigma_{v}-\alpha P_{p}\right)}{(1-v)}+\alpha P_{p}
$$

Where $v$ is the Poisson's ratio ( 0.2 for sand), $\alpha$ is the Biot's factor ( 1.0 for sand). In our case, the estimated minimum horizontal stress is $0.59 \mathrm{psi} / \mathrm{ft}$.

\section{Maximum horizontal stress and pore pressure}

The maximum horizontal stress is determined from observations of image logs and available rock mechanical data. Through breakout observation in some wells, the minimum horizontal stress is in the direction of $35-50^{\circ}$, and correspondingly a maximum stress direction of $122-140^{\circ}$. In addition, the breakout analysis uses the stress polygon approach to estimate the magnitude of the maximum horizontal stress. Our approach is based on Mohr-Coulomb theory [8]. For the breakout area to occur, it is assumed that the Mohr circle, representing bay hoop stress and radial stress, equals the failure envelope (defined by the cohesive strength and friction angle of the rock material). Equation 8 shows the maximum horizontal stress corresponding to the failure condition:

$$
\sigma_{H}=\frac{C o+(P w-\alpha P p)(\tan \beta)^{2}+\sigma_{h}+P w+\alpha P p}{3}
$$




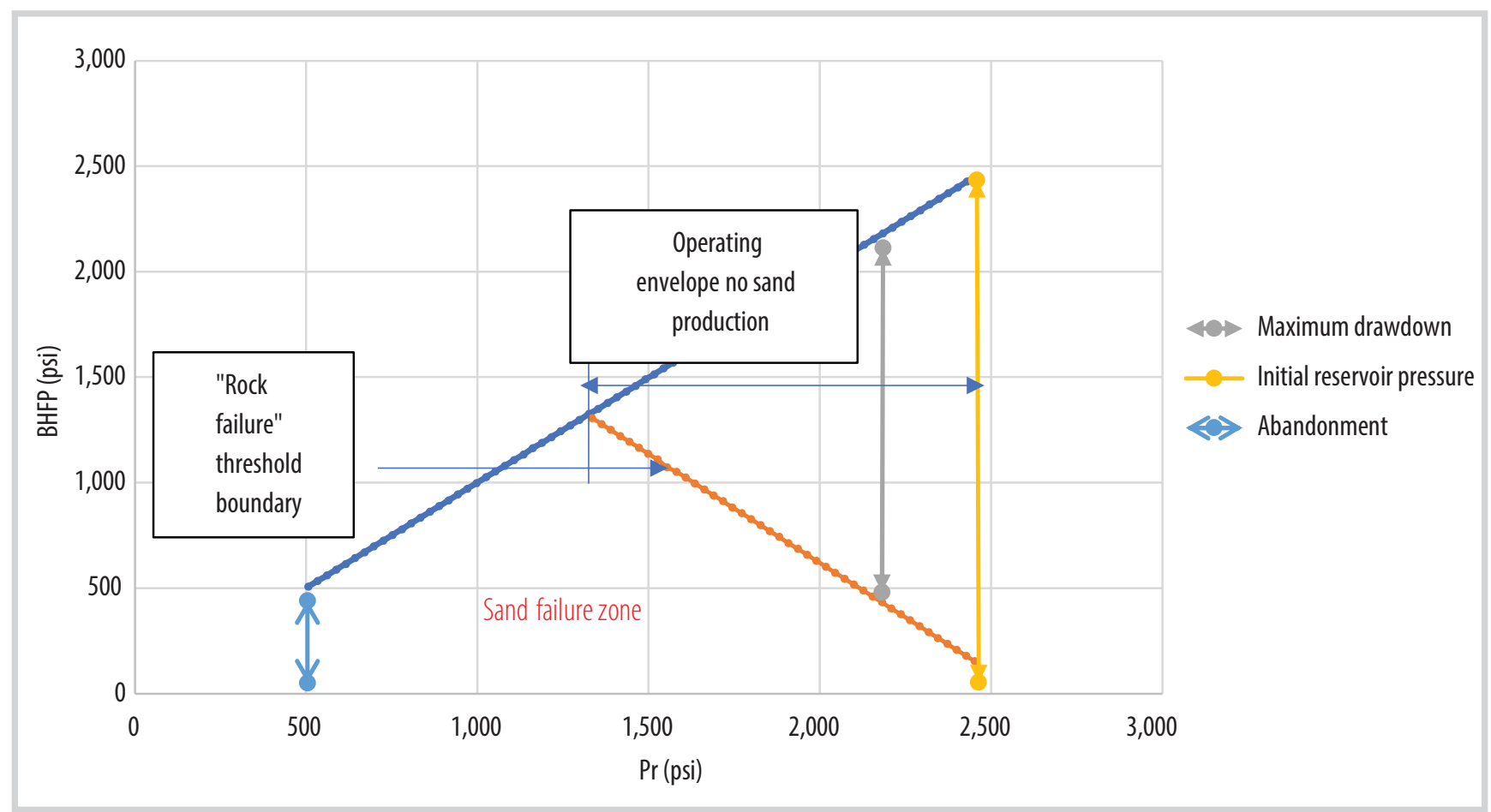

Figure 5. Sand-free operating envelope.

Our data showed the reservoir interval with normal pressure regime of $0.441 \mathrm{psi} / \mathrm{ft}$.

\section{Sanding onset assessment}

For a vertical well with open hole completion and the input data as illustrated in the previous parts, a sand production model is developed to predict the downhole condition (critical drawdown) required for rock failure, and hence potential sand production [9]. Our model uses the laboratory results of TWC. The tangential stress around an opening (perforation or open hole) is calculated and compared to the effective formation strength. In Figure 5, the BHFP is calculated by Equation 1 and the reservoir pressure at any given time. The result shows the potential reservoir pressure and bottom hole flowing pressure that results in rock failure. When the BHFP $>\mathrm{Pr}$, there is no sand production (above blue line). The red line represents the rock failure threshold, which is for a TWC strength and single perforation or well orientation in this case. Any failing point below the sand failure zone indicates that a failure condition has occurred for the relevant cavity, and that sand production is assumed. Any failing point above the red line represents a no failure condition and sandfree hydrocarbon production. In our case, the maximum drawdown is 2,380 psi and the reservoir pressure should be managed above 1,280 psi.

\section{Conclusions}

This paper presents a method for sand production prediction from laboratory and field data. The method has been applied to a case to assess sanding risk in a proposed well, helping minimise sanding risk in the future. Sanding evaluation results using the predictive model presented in this paper should be verified by field observations. Sanding evaluations are performed over the lifetime of a field from current to final (abandonment) reservoir pressures and at pressure conditions corresponding to a decrease of up to 500 psi for all existing production wells during their life circle. Some main points can be concluded through this study:

- Rock strength testing is required prior to the execution of a geomechanical study itself;

- The best model for calculating log-derived strength UCS/TWC can be selected using combination of conventional laboratory triaxial testing and nondestructive methods;

- The maximum drawdown is 2,380 psi and the reservoir pressure should be managed above 1,280 psi. 


\section{References}

[1] Jong-Won Choi, Geomechanics of subsurface sand production and gas storage. Georgia Institute of Technology, 2011.

[2] R.S. Wulan, Y. Susilo, Y.S. Hendra, D. Ramdan, and A. Mansur, "Development strategies of soft-friable carbonate gas reservoirs through horizontal open hole gravel packed completions: APN field - offshore West Java", International Petroleum Technology Conference, Dubai, UAE, 4 - 6 December 2007. DOI: 10.2523/IPTC-11560-MS.

[3] A. Joseph, L.C. Akubue, and A.B. Oriji, "Sanding prediction using rock mechanical properties", Nigeria Annual International Conference and Exhibition, Lagos, Nigeria, 6 - 8 August 2012. DOI: 10.2118/162945-MS.

[4] Mazen Y. Kanj and Younane Abousleiman, "Realistic sanding predictions - A neural approach", SPE Annual Technical Conference and Exhibition, Houston, Texas, 3 - 6 October 1999. DOI: 10.2118/56631-MS.

[5] Bernt Aadnøy and Reza Looyeh, Petroleum rock mechanics - Drilling operations and well design, $1^{\text {st }}$ edition. Gulf Professional Publishing, 2011.
[6] Mark D. Zoback, Reservoir geomechanics. Stanford University, 2009.

[7] M. Azad, G. Zargar, R. Arabjamaloei, A. Hamzei, and M.A. Ekramzadeh, "A new approach to sand production onset prediction using artificial neural networks", Petroleum Science and Technology, Vol. 29, No. 19, pp. 1975 - 1983, 2011. DOI: 10.1080/10916460903551081.

[8] Nguyen Van Hung, "Overview of geomechanics and its applications to petroleum industry - A case study for minimum overbalance pressure calculation", CIGOS 2019: Innovation for Sustainable Infrastructure, Singapore: Springer, 2020, pp. 739 - 744. DOI: 10.1007/978-981-150802-8_117.

[9] Ian D. Palmer, Nigel Higgs, Ion Ispas, Kirk Baksh, and Kimberly Diane Krieger, "Prediction of sanding using oriented perforations in a deviated well, and validation in the field", SPE International Symposium and Exhibition on Formation Damage Control, Lafayette, Louisiana, USA, 15 17 February 2006. DOI: 10.2118/98252-MS. 